\title{
ANALISIS SENYAWA KIMIA PADA TIGA JENIS JAHE DAN PENGGUNAANNYA UNTUK KEPERLUAN INDUSTRI
}

\author{
Titiek Pujilestari ') \\ Nami Lestari ${ }^{2}$ )
}

\begin{abstract}
The essential oil distillation of local gingers (emprit ginger, red ginger and elephant ginger) from east Borneo make in two condition; i.e freh and dry condition was carry out. The essential oil produce from fresh ginger having much amount of chemical compound than the dry condition. In the fresh condition, elephant ginger have 81 kind of compounds, red ginger have $59 \mathrm{kind}$ of compounds, emprit ginger have 56 kind of compounds, mean while in dry condition the amount of ginger'compound is decrease. The elephant ginger became 76 kind of compounds, red ginger 46 kind of compounds, emprit ginger 40 kind of compounds. The ginger rompound can use as perfume flavor, insecticide, analytical reagent, indicator, food flavor, coloring matters, cosmetic, anti cancer material and anti oxidant. Three kind of ginger in the fresh or dry condition having three same compound, they are C-citral, Arcurcumene, and Beta sesquipphellandrene.
\end{abstract}

Key words : ginger, chemical compound

\section{PENDAHULUAN}

Tahe (Zingiber officinale) merupakan salah satu jenis rempah-rempah penting yang banyak dimanfaatkan orang baik dalam bentuk segar maupun dalam bentuk jahe olahan. Produksi jahe di Kalimantan Timur pertahun cukup besar yaitu 2.454 ton, daerah penghasil jahe berada di Samarinda, Kutai Kartanegara, Kutai Barat, Tarakan dan Balikpapan (Lestari, N. 2006).

Rimpang jahe mengandung minyak atsiri $13 \%$ dapat diekstrak dengan cara penyulingan. Minyak atsiri adalah senyawa mudah menguap yang tidak larut dalam air dan dapat dipisahkan dari jaringan tanaman melalui proses destilasi / penyulingan. Minyak atsiri akan menguap dari jarigan tanaman bersama uap air yang terbentuk atau bersama uap air yang dilewatkan pada bahan. Penyulingan minyak atsiri dilakukan dengan cara pengukusan, metoda ini paling sering digunakan karena mutu produk cukup baik, proses cukup efisien dan harga alat tidak terlalu mahal (http : // www ristek.go.id).

Minyak atsiri jahe dapat digunakan untuk berbagai keperluan antara lain sebagai bumbu masak, pemberi aroma dan rasa pada makanan seperti kue, biskuit, kembang gula dan berbagai minuman ringan. Minyak atsiri jahe dapat juga digunakan pada industri obat, minyak wangi dan industri jamu tradisional.

Jenis, umur, tempat tumbuh, musim dan cara bercocok tanam jahe berpengaruh pada senyawa kimia minyak atsiri jahe yang dihasilkan, oleh karena itu perlu dilakukan penelitian dengan tujuan mengetahui tentang kandungan senyawa kimia minyak atsiri jahe asal Kalimantan Timur agar diperoleh kepastian penggunaannya dalam berbagai kepentingan industri.

\section{BAHAN DAN METODA}

Bahan dan Peralatan

Bahan yang digunakan dalam penelitian adalah tiga jenis jahe yaitu jahe gajah (putih besar), jahe merah (warna merah) dan jahe emprit (putih kecil). Ketiga jenis jahe dibeli dipasar yang berada di Samarinda Kalimantan Timur, dipilih yang kondisinya tidak busuk, tidak cacat dan masih segar. 
Peralatan yang digunakan dalam penelitian ini berupa; timbangan, pisau, nyiru, botol dan satu unit alat penyuling untuk mendapatkan minyak atsiri. Untuk pengujian mutu minyak atsiri digunakan alat antara lain; gelas ukur, erlenmeyer, buret, timbangan dan polarimeter, sedang untuk mengetahui kandungan dan jenis senyawa kimia digunakan GCMS ( Gas Chromatography Mass Spectrophotometry).

Metoda

Penyulingan jahe dilakukan dengan sistim pengukusan dalam keadaan segar/basah dan yang telah dikeringkan. Pilih jahe yang baik, segar dan tidak cacat kemudin cuci hingga bersih. Lakukan pengecilan ukuran dengan cara mengiris tipis-tipis dengan ketebalan 2-4 mm. Untuk penyulingan cara kering, jahe dengan irisan tipis tersebut dikeringkan dalam oven pada suhu $60-70^{\circ}$ C sampaikadar air sekitar $10-15 \%$.

Siapkan alat penyuling dan bersihkan bagian dalam dandang, kemudian isikan air bersih sampai batas bawah darialas angsang atau tempat bahan irisan jahe akan dikukus.

Masukkan bahan potongan jahe yang telah diiris tipis sebanyak $4-5 \mathrm{~kg} \quad$ kedalam ketel yang menyerupai dandang. Usahakan potongan rimpang seseragam mungkin, untuk menghindari bias dan agar minyak atsiri yang keluar dari bahan dapat seragam. Bahan disusun dengan memperhatikan adanya rongga sehingga pengisian bahan tidak terlalu padat dan penuh agar penetrasi uap dapat merata .

Setelah bahan tersusun baik, pastikan penutup ketel tertutup dengan sempurna yang ditandai dengan tidak ada kebocoran uap dari celah tutup dan penyulingan siap dilakukan. Penggunaan api diusahakan tidak terlalu besar karena dapat menyebabkan gosong yang akan berpengaruh pada mutu minyak atsiri.

Pengujian dilakukan dilaboratorium Kimia dan Mikrobiologi Hasil Pertanian, Fakultas Pertanian Universitas Mulawarman Samarinda terhadap jahe yang akan disuling yaitu; kadar air, dan kadar minyak atsiri; serta karakteristik minyak atsiri jahe meliputi; berat jenis, indek bias, kelarutan dalam alkohol dan bilangan asam. Disamping itu juga dilakukan pengujian senyawa kimia ketiga jenis jahe pada kondisi segar dan kering dengan menggunakan GCMS di Laboratorium Kimia LIPI Serpong.

\section{HASIL DAN PEMBAHASAN}

Telah dilakukan pengolahan minyak atsiri dari tiga jenis jahe yaitu jahe gajah, merah dan emprit yang dilakukan dengan cara penyulingan pada kondisi segar/basah maupun pada kondisi kering.

Kadar air jahe segar dari tiga jenis jahe berkisar $70,31 \quad 71,15 \%$ dan jahe kering sekitar 9,50 $14 \%$ dan setelah dilakukan penyulingan diperoleh minyak atsiri jahe kering lebih tinggi dari pada jahe segar, seperti pada Tabel 1.

Tabel 1. Rata-rata Pengujian Jahe Gajah, Merah dan Emprit (dalam \%)

\begin{tabular}{|c|c|c|c|}
\hline No. & Jenis Jahe & Kadar Air & Kadar Minyak Atsiri \\
\hline 1 & Jahe gajah segar & 71,15 & 0,36 \\
2 & Jahe gajah kering & 14 & 1,72 \\
3 & Jahe merah segar & 70,48 & 0,32 \\
4 & Jahe merah kering & 9,9 & 2,3 \\
5 & Jahe emprit segar & 70,31 & 0,45 \\
6 & Jahe emprit kering & 9,5 & 2,3 \\
\hline
\end{tabular}

Kadar air akan berpengaruh terhadap kadar minyak atsiri yang diperoleh, hal ini karena pada jahe segar / basah bobot bahan padatan sekitar $30 \%$ sedangkan pada jahe kering sekitar 90 $\%$ bobot bahan padatannya, dengan demikian kadar minyak atsirijahe kering juga lebih tinggi.

Berdasar hasil pengujian terhadap karakteristik minyak atsiri dari ketiga jenis jahe dengan cara penyulingan yang dilakukan dengan metoda pengukusan rata-rata memberikan hasil yang 
memenuhi standar mutu minyak jahe, kecuali pada bilangan asam yang memberikan hasil diatas yang dipersyaratkan menurut SNI. 06-1312-1998 tentang Syarat Mutu Minyak Atsiri (Ginger Oil) karena lebih besar dari $2,0 \mathrm{mg} \mathrm{KOH} / \mathrm{g}$ seperti pada Tabel 2.

Tabel 2. Pengujian Karakteristik Minyak Atsiri Jahe

\begin{tabular}{|c|c|c|c|c|c|}
\hline Jenis Jahe & Ulangan & $\begin{array}{c}\text { Berat } \\
\text { Jenis }\end{array}$ & $\begin{array}{c}\text { Indeks } \\
\text { Bias }\end{array}$ & $\begin{array}{c}\text { Kelarutan dlm } \\
\text { alkohol }\end{array}$ & $\begin{array}{c}\text { Bilangan Asam } \\
\text { (mg KOH/g) }\end{array}$ \\
\hline \multirow{3}{*}{ Jahe Gajah } & 1 & 0,887 & 1,479 & $1: 04$ & 2,343 \\
\cline { 2 - 6 } & 2 & 0,879 & 1,482 & $1: 05$ & 2,315 \\
\cline { 2 - 6 } & 3 & 0,882 & 1,481 & $1: 04$ & 2,402 \\
\hline \multirow{3}{*}{ Jahe Merah } & 1 & 0,895 & 1,488 & $1: 06$ & 2,672 \\
\cline { 2 - 6 } & 2 & 0,891 & 1,483 & $1: 05$ & 2,427 \\
\cline { 2 - 6 } & 3 & 0,894 & 1,485 & $1: 06$ & 2,541 \\
\hline \multirow{3}{*}{ Jahe Emprit } & 1 & 0,895 & 1,489 & $1: 06$ & 2,578 \\
\cline { 2 - 6 } & 2 & 0,896 & 1,482 & $1: 05$ & 2,506 \\
\cline { 2 - 6 } & 3 & 0,892 & 1,487 & $1: 05$ & 2,614 \\
\hline
\end{tabular}

Berat jenis minyak atsiri dari tiga jenis jahe yaitu jahe gajah, jahe merah dan jahe emprit berkisar antara $0,879-0,896$ yang berarti dari ketiga jenis jahe tersebut mempunyai berat jenis yang hampir sama. Berat jenis merupakan salah satu kriteria dalam menentukan mutu dan kemurnian minyak atsiri.

Berat jenis minyak atsiri merupakan perbandingan.antara berat minyak dengan berat air pada volume air dan minyak yang sama sehingga basarnya berat jenis berhubungan dengan fraksi berat komponen yang terkandung didalamnya.

Indeks bias dalam minyak atsiri jahe 1,479-1,489, hal ini sesuai dengan yang dipersyaratkan dalam Standar Nasional Indonesia tentang syarat mutu minyak jahe yaitu 1,48531,4920 . Indeks bias merupakan perbandingan antara kecepatan cahaya didalam udara dengan kecepatan cahaya didalam bahan pada suhu tertentu. Indeks bias minyak atsiri berhubungan erat dengan komponen yang tersusun dalam minyak atsiri yang diuji (ferry-atsiri.blogspot.com).

Minyak atsiri jahe gajah mempunyai indeks bias paling rendah dibanding dengan minyak atsiri jahe merah dan jahe emprit, hal ini berarti komponen-komponen yang terkandung dalam minyak atsiri jahe gajah berbeda dengan yang lainnya dan memiliki sifat mudah untuk membiaskan cahaya yang datang.

Kelarutan minyak atsiri dalam alkohol rata-rata $1: 4 ; 1: 5 ; 1: 6$. Menurut Guenther dalam htpp://fery.atsiri.blogspot.com bahwa kelarutan minyak dalam alkohol ditentukan oleh jenis komponen kimia yang terkandung dalam minyak. Makin tinggi kandungan terpen makin rendah daya larutnya, sehingga makin kecil kelarutan minyak atsiri pada alkohol maka kualitas minyak atsiri semakin baik.

Derajad keasaman tiga jenis minyak atsiri jahe gajah, jahe merah dan jahe emprit berkisar $2,315-2,672 \mathrm{mg} \mathrm{KOH} / \mathrm{g}$, hal ini lebih tinggi dari yang dipersyaratkan maks $2,0 \mathrm{mg} \mathrm{KOH} / \mathrm{g}$. Adanya asam bebas dalam minyak atsiri dapat merubah bau khas dari minyak atsiri. Semakin tinggi bilangan asam akan berpengaruh terhadap mutunya karena apabila kontak dengan udara atau berada pada kondisi yang lembab akan mengalami reaksi oksidasi dengan udara akan membentuk senyawa asam.

Hasil pengujian senyawa kimia dari tiga jenis jahe menggunakan alat GCMS, adalah sebagai berikut; pada keadaan segar dari jahe gajah didapat 81 senyawa, jahe merah 59 senyawa,, dan jahe emprit 56 senyawa, sedangkan pada keadaan kering dari jahe gajah didapat 73 senyawa, jahe merah 46 senyawa,, dan jahe emprit 40 senyawa. Jumlah senyawa yang terdeteksi dari ketiga jenis jahe ternyata berbeda, baik yang diuji dalam keadaan basah maupun kering, jahe gajah memiliki kandungan yang paling banyak, dan yang terendah adalah jahe emprit.

Pada keadaan kering jumlah senyawa yang terdeteksi dari ketiga jenis jahe mengalami penurunan. Disamping itu ternyata bahwa pada kondisi segar dan simplisia /dikeringkan juga memberikan jumlah dan jenis senyawa yang berbeda pula, yang ditunjukkan dengan adanya senyawa yang sebelumnya terdeteksi pada kondisi segar/basah tetapi setelah pengeringan ternyata senyawa tersebut tidak terdeteksi, sebaliknya ada senyawa yang tidak terdeteksi dalam 
Jahe tetapi setelah proses pengeringan justru senyawa tersebut muncul dan terdeteksi cukup dominan. Keadaan ini disebabkan dalam pengeringan terjadi penguapan air dan senyawa yang mudah menguap serta pelepasan senyawa yang tadinya terikatmenjadi bebas.

Dari senyawa kimia yang terdeteksi dipilih yang mempunyai konsentrasi dominan dengan persentase area yang tertinggi, dipilih sembilan senyawa yang dominan dalam jahe dengan pertimbangan masing-masing jahe mempunyai senyawa lebih dari 50 senyawa. Senyawa kimia hasil pengujian dari tiga jenis jahe disajikan pada Tabel 4

Tabel 4. Senyawa Kimia Jahe Gajah, Merah dan Emprit

\begin{tabular}{|c|c|c|c|c|c|c|c|}
\hline \multirow{3}{*}{ No. } & \multirow{3}{*}{ Nama Senyawa } & \multicolumn{6}{|c|}{$\%$ Kandungan Senyawa } \\
\hline & & \multicolumn{2}{|c|}{ Jahe Gajah } & \multicolumn{2}{|c|}{ Jahe Merah } & \multicolumn{2}{|c|}{ Jahe Emprit } \\
\hline & & Segar & Kering & Segar & Kering & Segar & Kering \\
\hline 1 & Sabinene & 21,03 & - & 3,98 & - & - & - \\
\hline 2 & Citrolnellol & 4,2 & 3,96 & - & - & - & - \\
\hline 3 & Z-Citral & 4,17 & 2,57 & 8,88 & 4,4 & 8,14 & 6,32 \\
\hline 4 & $\alpha-$ Zingiberen & 0,12 & 22,51 & 22,72 & 16,13 & - & 17,16 \\
\hline 5 & $\beta$-Sesquiphellandrene & 6,76 & 8,05 & 11,46 & 8,62 & 5,57 & 14,6 \\
\hline 6 & Ar-Curcumene & 5,21 & 5,72 & 6,87 & 8,71 & $-4,37$ & 12,62 \\
\hline 7 & 1,8-Cineole & - & 6,18 & - & 4,03 & - & - \\
\hline 8 & Geraniol & 5,29 & 7 & 10,38 & 10,92 & - & 13,02 \\
\hline 9 & Geranial & 6,88 & 4,27 & - & - & - & - \\
\hline 10 & $\beta$ - Bisabolene & - & 5,27 & 11,39 & - & - & 10,48 \\
\hline 11 & a-Farnesene & 4,06 & 8,04 & - & 10,08 & - & 1,12 \\
\hline 12 & 3,7 Decadiene & - & - & - & - & 11,91 & - \\
\hline 13 & 3-Buten-2-ol & - & - & - & - & 4,74 & - \\
\hline 14 & 9,12 - Octadecadiene Orchid & - & - & - & - & 14,13 & - \\
\hline 15 & E ugenol & - & - & 2,17 & - & - & - \\
\hline 16 & Geranyl Acetat & - & - & 2,99 & - & - & - \\
\hline 17 & Cyclobutene & - & - & - & - & 2,85 & - \\
\hline 18 & 5 -|so propyl- 6 & - & . & . & - & 2,97 & 7,98 \\
\hline 19 & Camphene & - & - & 5,95 & - & - & 2,74 \\
\hline 20 & Endo Borneol & - & $=$ & 2,06 & - & - & - \\
\hline
\end{tabular}

Terdapat tiga senyawa kimia yang keberadaannya selalu muncul pada ke tiga jenis jahe baik dalam keadaan kering maupun basah, yaitu Z-citral, Ar curcumene, dan $\beta$ sesquiphellandrene. Kandungan Z-citral tertinggi didapat dari jahe merah segar yaitu sebesar $8,88 \%, \beta$ Sesquiphellandrene tertinggi didapat dari jahe emprit kering yaitu $14,60 \%$, Ar Curcumene tertinggi didapat dari jahe empit yaitu sebesar $12.62 \%$. Senyawa a Zingiberen, Geraniol, dan a Farnesene juga terdapat pada ketiga jenis jahe tersebut tetapi hanya dalam kondisi kering. Senyawa a Farnesene baru muncul pada jahe merah kering, sedangkan senyawa a Zingiberen, Geraniol, dan a Farnesene juga baru muncul pada jahe emprit. Jahe emprit merupakan jenis jahe yang kandungan senyawa kimianya relative berbeda antara basah dan kering, terdapat beberapa senyawa dalam keadaan basah tetapi setelah dikeringkan senyawa tersebut menjadi tidak didapat begitu pula sebaliknya. Guenther,E. 1987 menyatakan bahwa dalam minyak atsiri jahe diantaranya adalah zingiberen, camphene, phellandrene, citral, sineol dan zingiberol (terpen alkohol).

Perbedaan senyawa yang diperoleh dari jenis dan keadaan jahe (segar/kering) memberikan petunjuk bahwa agar jahe dapat dimanfaatkan secara maksimal sesuai dengan tujuan penggunaan maka pemilihan jenis dan keadaan jahe perlu mendapat pertimbangan yang lebih seksama.

Dari beberapa kandungan senyawa kimia jahe maka dapat diketahui kegunaan masingmasing senyawa untuk berbagaikeperluan sesuai dengan sifat dan karakteristik yang terkandung 
dalam senyawa kimia. Mengingat banyaknya senyawa kimia yang terdapat pada ketiga jenis jahe maka untuk mengetahui kegunaannya hanya diambil beberapa senyawa dominan yang mempunyai persen area tinggi dalam setiap jenis jahe.

Senyawa kimia yang tidak dominan dengan prosen kandungan yang rendah bukan berarti tidak berpengaruh terhadap sifat dan karakteristik jahe,bisa juga dengan kandungan rendah tetapi mempunyai fungsi dan karakteristik yang dominan terhadap sifat jahenya, mengingat senyawasenyawa tersebut saling berinteraksi dalam membentuk sifat jahe.

Rangkuman beberapa hasil senyawa kimia yang mempunyai persen area tinggi ternyata mempunyai sifat karakteristik, fungsi dan sifat toksik dari jahe disajikan pada Tabel 5.

Tabal 5. Karakteristik, Fungsi dan Sifat Toksisitas Senyawa Aktif Jahe

\begin{tabular}{|c|c|c|c|c|}
\hline No. & Senyawa & Karakteristik & Fungsi & Sifat Toksit \\
\hline 1 & $\begin{array}{l}\text { Sabinene } \\
\mathrm{C}_{10} \mathrm{H}_{15}\end{array}$ & $\begin{array}{l}\text { Cairan tidak berwarna sampai kuning } \\
\text { pucat, tidak larut dalam air, larut dalam } \\
\text { alkohol, kekuatan bau sedang, } \\
\text { direkomendasikan mencium pada } \\
\text { larutan } \leq 10 \% . \text { Mm }=136,23 \mathrm{~g} / \mathrm{mol}, \mathrm{BM} \\
=136,23404, \mathrm{rm}=43,76 \pm 0,4 \mathrm{~cm}^{3}, \mathrm{~d}= \\
0,88 \pm 0,1 \mathrm{~g} / \mathrm{cm}^{3}, \text { polaritas }=17,34 \pm \\
0,510-24 \mathrm{~cm}^{3}, \text { ir }=1,483 \pm 0,03 \text {, titik } \\
\text { didih }=163-164^{\circ} \mathrm{C} \text { pada } 76 \mathrm{~cm} \mathrm{Hg} \text {, } \\
\text { tegangan permukaan } 27,0 \pm 5,0 \\
\text { dyne } / \mathrm{cm} \text {. }\end{array}$ & $\begin{array}{l}\text { Pemberi aroma pada } \\
\text { parfum. }\end{array}$ & $\begin{array}{l}\text { Disarankan dosis penggu } \\
\text { naan } 3,0000 \% \text { pada kon } \\
\text { sentrasi parfum, apabila } \\
\text { melebihi batas akan meng } \\
\text { alami keracunan }\end{array}$ \\
\hline 2 & $\begin{array}{l}\text { Geraniol } \\
\mathrm{C}_{10} \mathrm{H}_{18} \mathrm{O}\end{array}$ & $\begin{array}{l}\text { Tidak larut dalam air dan gliserol, larut } \\
\text { dalam pelarut organik (alkohol, eter). } \\
\text { Masa molar }=154,25 \mathrm{~g} / \mathrm{mol} \text {, densitas }= \\
0,889 \mathrm{~g} / \mathrm{cm}^{2} \text { pada } 15^{\circ} \mathrm{C} \text {, indek refraksi } \\
=1,4710-1,4780 \text {, titik leleh }=-15^{\circ} \mathrm{C} \text {, } \\
\text { titik didih }=229^{\circ} \mathrm{C}\end{array}$ & \begin{tabular}{l|} 
Menjadi tanaman \\
efektif untuk pembasmi \\
serangga, menarik \\
lebah, berbau seperti \\
mawar, sering \\
digunakan sebagai \\
parfum. \\
\end{tabular} & $\begin{array}{l}\text { Toksik terhadap manusia, } \\
\text { kanker, organ reproduksi. } \\
\text { dan organ saraf. }\end{array}$ \\
\hline 3 & $\begin{array}{l}\text { Beta ses- } \\
\text { quiphellan- } \\
\text { drene } \\
\mathrm{C}_{15} \mathrm{H}_{24}\end{array}$ & $\begin{array}{l}\text { Merupakan seskuiterpen mi nyak jahe, } \\
\text { berupa cairan tidak berwarna sampai } \\
\text { kuning pucat, memiliki kekuatan bau } \\
\text { sedang, tetapi disrankan untuk } \\
\text { mencium bau pada direkomendasikan } \\
\text { mencium pada larutan } \leq 10 \% \text {. rm }= \\
68,53 \pm 0,4 \mathrm{~cm}^{3} \text {, densitas }=0,85 \pm 0,1 \\
\mathrm{~g}^{\prime} \mathrm{cm}^{3} \text {, polaritas }=27,17 \pm 0,510-24 \\
\mathrm{~cm}^{3} \text {, indek refraksi }=1,482 \pm 0,03 \\
\text { tegangan permukaan }=28,3 \pm 5,0 \\
\text { dyne } / \mathrm{cm}, \mathrm{BM}=204,35106, \text { titik didih } \\
270-272^{\circ} \mathrm{C} \text { pada tekanan } 76 \mathrm{~cm} \mathrm{Hg} \text {, } \\
\text { titik nyala }=226,00^{\circ} \mathrm{F} \text {. }\end{array}$ & $\begin{array}{l}\text { Memiliki aktivitas anti- } \\
\text { tumor secara in vivo } \\
\text { maupun in vitro, serta } \\
\text { pembasmi serangga. }\end{array}$ & - \\
\hline 4 & $\begin{array}{l}\mathrm{Ar} \\
\text { Curcume } \\
\text { ne } \\
\mathrm{C}_{15} \mathrm{H}_{22}\end{array}$ & $\begin{array}{l}\text { Tidak larut dalam air, tetapi larut } \\
\text { dalam alkohol. } \mathrm{Rm}=68,32 \pm 0,3 \mathrm{~cm}^{3} \text {, } \\
\text { densitas }=0,837 \pm 0,06 \mathrm{~g} / \mathrm{cm}^{3}, \\
\text { polaritas }=27,08 \pm 0,510-24 \mathrm{~cm}^{3}, \text { ir }= \\
1,501 \pm 0,02, \text { titik didih }=275-277^{\circ} \mathrm{C} \\
\text { pada tekanan } 76 \mathrm{~cm} \mathrm{Hg} \text {, titik leleh }= \\
177-179^{\circ} \mathrm{C} \text {, titik nyala }=243,00^{\circ} \mathrm{F}, \\
\text { tegangan permukaan }=29,9 \pm 3,0 \\
\text { dyne } / \mathrm{cm} \text {. }\end{array}$ & $\begin{array}{l}\text { Sebagai bahan } \\
\text { pemberi aroma pada } \\
\text { parfum. }\end{array}$ & $\begin{array}{l}\text { Bersifat racun bila } \\
\text { penggunaan nya } \\
\text { melebihibatas. }\end{array}$ \\
\hline
\end{tabular}




\begin{tabular}{|c|c|c|c|c|}
\hline No. & Senyawa & Karakteristik & Fungsi & Sifat Toksit \\
\hline 5 & $\begin{array}{l}\text { Zingibere } \\
\text { ne } \\
\mathrm{C}_{15} \mathrm{H}_{24}\end{array}$ & $\begin{array}{l}\text { Merupakan seskuiterpen mo nosiklik } \\
\text { yang menyusun secara dominan } \\
\text { minyak jahe, berupa cairn tidak } \\
\text { berwarna. Massa molar }=204,35 \mathrm{~g} / \mathrm{mol} \text {, } \\
\text { BM }=204,34 ; \text { densitas } 0,8713 \mathrm{~g} / \mathrm{cm}^{3} \\
\text { pada } 20^{\circ} \mathrm{C} \text {, titik didih }=134-135^{\circ} \mathrm{C} \text { pada } \\
15 \text { Torr, titik leleh }=97-98^{\circ} \mathrm{C} \text {. }\end{array}$ & $\begin{array}{l}\text { Sebagai bahan } \\
\text { pewarna, reagen } \\
\text { analitik, indikator asam } \\
\text { basa, berwarna merah } \\
\text { kecoklatan jika } \\
\text { direaksikan dengan al } \\
\text { kali, dan berwarna } \\
\text { kuning jika direaksikan } \\
\text { dengan asam. }\end{array}$ & - \\
\hline 6 & $\begin{array}{l}\text { Zingiberol } \\
\mathrm{C}_{15} \mathrm{H}_{2 \mathrm{f}} \mathrm{O}\end{array}$ & Berbau harum, berat molekul $=222,36$ & $\begin{array}{l}\text { Sebagai bahan antisel } \\
\text { kanker dan anti } \\
\text { oksidan. }\end{array}$ & - \\
\hline 7 & $\begin{array}{l}\text { Cineole } \\
\mathrm{C}_{10} \mathrm{H}_{18} \mathrm{O}\end{array}$ & $\begin{array}{l}\text { Berupa cairan tidak berwarna. } \\
\text { Massa molar }=154,249 \mathrm{~g} / \mathrm{mol} \text { densitas } \\
=0,9225 \mathrm{~g} / \mathrm{cm}^{3} \text {, titik leleh }=1,5^{\circ} \mathrm{C} \\
\left(274,6^{\circ} \mathrm{K}\right) \text {, titik didih }=176-177^{\circ} \mathrm{C}(449 \\
\left.-450^{\circ} \mathrm{K}\right) \text {. }\end{array}$ & $\begin{array}{l}\text { Pemberi rasa/ aroma, } \\
\text { sebagai bahan } \\
\text { pewangi, kosmetik, ba } \\
\text { han baku medicinal, } \\
\text { pembasmi serangga. }\end{array}$ & $\begin{array}{l}\text { Bersifat racun melalui } \\
\text { pencernaan makanan, } \\
\text { kulit atau pengisapan } \\
\text { pada dosis diatas } \\
\mathrm{LD}_{\text {so }}=2480 \mathrm{mg} / \mathrm{kg} \text { rat. } \\
\text { Dapat berpengaruh akut } \\
\text { pada kesehatan } \\
\text { pernapasan, dan sistem } \\
\text { saraf. }\end{array}$ \\
\hline 8 & $\begin{array}{l}\text { A I p h a } \\
\text { Farnesene } \\
\mathrm{C}_{15} \mathrm{H}_{24}\end{array}$ & $\begin{array}{l}\text { Tidak larut dalam air, tetapi larut } \\
\text { dalam alkohol. Berat molekul }= \\
204,35 \text {, boiling poin }=260^{\circ} \mathrm{C} \text {, densitas } \\
=0,844-0,8790 \mathrm{~g} / \mathrm{ml} \text { pada } 25^{\circ} \mathrm{C} \text {, } \\
\text { indeks refraksi }=1,490-1,505 \text {, flash } \\
\text { poin }=110^{\circ} \mathrm{C} \text {. }\end{array}$ & $\begin{array}{l}\text { Sebagai konstituen } \\
\text { pada lapisan buah } \\
\text { apel dan pear. }\end{array}$ & - \\
\hline 9 & $\begin{array}{l}\text { Bisabolene } \\
\mathrm{C}_{15} \mathrm{H}_{24}\end{array}$ & $\begin{array}{l}\text { Tidak larut dalam air, tetapi larut dalam } \\
\text { alkohol, beraroma buah-buahan, } \\
\text { kekuatan bau sedang, cairan tidak } \\
\text { berwarna sampai kuning pucat. Berat } \\
\text { molekul }=204,351 \text {; refraktivitas molar } \\
=68,52 \pm 0,03 \mathrm{~cm}^{2} \text {, densitas }=0,867 \pm \\
0,06 \mathrm{~g} / \mathrm{cm}^{3} \text {, polaritas }=27,16 \pm 0,0510- \\
24 \mathrm{~cm}^{3} \text {, indeks refraksi }=1,493 \pm 0,02 ; \\
\text { titik didih }=148,0^{\circ} \mathrm{C} \text { pada } 1,8 \mathrm{~cm} \mathrm{Hg} \\
\text { atau } 261-263^{\circ} \mathrm{C} \text { pada } 76 \mathrm{cmHg} \text {, titik } \\
\text { nyala }=230^{\circ} \mathrm{F} \text {, tegangan permukaan }= \\
29,5 \pm 3,0 \text { dyne } / \mathrm{cm} \text {, dan tekanan uap } \\
=0,0300 \mathrm{mmHg} \text { pada } 20,0^{\circ} \mathrm{C} \text {. }\end{array}$ & $\begin{array}{l}\text { Sebagai pemberi cita } \\
\text { rasa/ aroma pada } \\
\text { parfum. }\end{array}$ & $\begin{array}{l}\text { Penyebab iritasi mata, } \\
\text { pada larutan } 10 \% \text { tidak } \\
\text { menyebabkan iritasi. } \\
\text { Disarankan leve } \\
\text { penggunaan maksimal } 10 \\
\% \text { dari konsentrasi } \\
\text { parfum, dan maksimal } 30 \\
\text { ppmuntukrasa/aroma. }\end{array}$ \\
\hline 10 & $\begin{array}{l}\text { Z-Citral } \\
\mathrm{C}_{10} \mathrm{H}_{70} \mathrm{O}\end{array}$ & $\begin{array}{l}\text { Cairan berwarna kuning muda, } \\
\text { sampai kuning, berat jenis }=0,881 \text { - } \\
0,891 \text { pada } 25^{\circ} \mathrm{C} \text {, indeks refraksi }= \\
1,478-1,490 \text { pada } 20^{\circ} \mathrm{C} \text {, titik didih }= \\
229,0-230,0^{\circ} \mathrm{C} \text { pada tekanan } 1 \mathrm{~atm}, \\
\text { dan flash piont }=101,67^{\circ} \mathrm{C} \text {. }\end{array}$ & $\begin{array}{l}\text { Digunakan untuk } \\
\text { kosmetik dan parfum. } \\
\text { Bila dicampur dengan } \\
\text { acetals, aldehid, dan } \\
\text { alkohol akan } \\
\text { menambah. }\end{array}$ & - \\
\hline
\end{tabular}

Sumber: 1. Bennet, H, 1947, Concise Chemical \& Technical Dictionary, Chemical Publishing Company, Inc, New York.

2. Lewis, RJ, 1993, Hawley, s Condensed Chemical Dictionary, Van Nostrand Reinhold Company, New York. 
Dari tabel 5 dapat dikemukakan bahwa kegunaan dari senyawa kimia ekstrak jahe antara lain sebagai pemberi aroma / parfum, pembasmi serangga, bahan pewarna, reagen analitik, indikator asarm, basa, pemberi rasa, bahan pewangi, kosmetik, bahan baku medicinal anti kanker dan antioksidan, konstituen pada lapisan buah apel dan pear.

Kandungan senyawa $\beta$ Sesquiphellandrene dari ketiga jenis jahe baik dalam keadaan basah maupun kering cukup besar yaitu berkisar antara $5,5714,60 \%$, hal ini berarti bahwa pada berbagai kondisi penggunaan jahe gajah, jahe merah dan jahe emprit asal Kalimantan Timur dapat digunakan sebagai bahan makanan fungsional yang memiliki aktivitas anti-tumor secara in vivo maupun in vitro

Disamping memiliki beberapa kegunaan juga memiliki sifat toksik yang perlu diperhatikan antara lain bersifat racun bila melampaui dosis penggunaan, penyebab kanker organ reproduksi, organ saraf dan penyebab iritasi pada mata. (Lewis, 1993)

\section{KESIMPULAN}

Jumlah senyawa kimia jahe kering lebih sedikit dari pada jahe segar. Jenis senyawa kimia pada jahe gajah, jahe merah dan jahe emprit yang keberadaannya selalu ada baik pada keadaan basah/segar atau kering adalah Z-citral, $\beta$ sesquiphellandrene dan Ar-curcumen. Jahe asal Kalimantan Timur dapat dimanfaatkan untuk berbagai keperluan sebagai pemberi aroma/parfum, pembasmi serangga, bahan pewarna, reagen analitik, indikator asam-basa, pemberi rasa, pewangi, kosmetik, bahan baku medicinal anti kanker dan anti oksidan, konstituen pada lapisan buah apel dan pear. Disamping itu juga dapat digunakan sebagai bahan makanan fungsional yang memiliki aktivitas anti-tumor secara in vivo maupun in vitro.

\section{DAFTAR PUSTAKA}

Anonim, 1998. Syarat Mutu Minyak Jahe ( Ginger Oil). SNI 06-1312-1998. Badan Standardisasi Nasional Indonesia. Jakarta.

Bennet,h. 1947. Concise Chemical \&Technical Dictionary. Chemical Publishing Company, Inc, New York.

Guenther, E. 1987.,Minyak Atsiri. Penerbit Universitas Indonesia. Jakarta.

Lewis, R.J. 1993. Hawley,s Condensed Chemical Dictionary. Van Nostrand Reinhold Company. New York

Lestari, N. 2006. Diversifikasi Pengolahan Jahe Menjadi Produk Awetan. Balai Riset dan Standardisasi Samarinda.

http : // ferry-atsiri.blogspot.com. Dikunjungi 29 Oktober 2009.

http:// www.ristek go. id. Dikunjungi 10 Agustus 2009. 